there are two points which seam to mo of suficient importance to warrant a briaf notice.

The firt is with regand to the use of the trochar in openin the windpipe. It would be rain here to enter into an elsborate discussion of the various modes of effecting this desirable object in cases of necessity. Much has been -ritten on the subject from the earliest history of surgery until the present time. Although Hippocrates refers to the necessity of this operation in cases of quinsy, "but not to be rentured upon until the agonies of death are present"; jet to Asclepiades, who practised at Rome, is attributed by Galen the honour of having first successfully practised this operation. Since his time, it has been advocated or condemned with equal confidence by a vast variety of writers. Paulus Afgineta, quoting the words of Antyllus, says, "We are to make an incision in the trachea, below the top of the windpipe, about the third or fourth ring-for this is a convenient situation-as being free of flesh, and because the vessels are placed at a distance from the part which is divided. Wherefore, bending the patient's head backward, 80 as to bring the windpipe the better into view, we are to make a transverse incision between two of the rings, so that it may not be the cartilage which is divided, but the membrane connecting the cartilages." The bugbear of avoiding the division of the cartilages is now, I need scarcely say, exploded. About the year 1695, Dekkers first proposed to open the trachea with a small trochar, furnished with a canula ; and Louis, in his Treatise on Bronchotomy, describes it as a happy thought, simplifying the operation, and rendering it easy of execution. Pauli claims the invention for Sanctorius, who recommends, for piercing the trachea, the same instrument which he proposed for tapping the abdomen.

Dr. Martin speaks of a very ingenious idea, which had been thrown out, to employ a double canula, one inside the other, so that the inner might be withdrawn and cleaned without interfering with the respiration. The use of the trochar has also been strongly adrocated in our own day, and improvements proposed in its construction, to which further allusion need not now be made. On the other hand, the authority of Van Swieten carries great weight, and strongly deprecates the use of the trochar. "This instrument", says he, "cannot be made to penetrate the trachea without great difficulty, on account of the great mobility of this part. I have sometimes tried it on dead bodies and on living animals, and the operation has appeared to me difficult, and the instrument likely to deviate"; for which reasons he deprecates it. I state my own opinion, partly founded upon the result of the case before us. This case was undoubtedly a very embarrassing one, and much complicated by the incision having, in the first instance, been made partly through the lower portion of the enlarged thyroid gland.

The second practical point is the question, What was the actual cause of that most urgent and distressing condition which threatened the life of our patient? I am not at all inclined to think that the dyspnoea was the effect of mechanical pressure on the windpipe; the bronchocele, it is true, was very hard, but it was also by no means large. I cannot doubt that it arose from nervous irritation, arising from the pressure of this hard gland upon the laryngeal branches of the eighth pair; and this is corroborated by the fact that, as long as any portion of the enlarged gland remained, the tomporary removal of the canula was at once followed by all the old symptoms; as soon as it was quite obliterated, the dyspnoea ceased, and the wound rapidly healed.

York, October 1853.

\section{TREATMENT OF DELIRIUM TREMENS WITHOUT NARCOTICS.}

By H. PAYNE, M.D.

Tre more successful methods of treating those disenses of the brain known as delirium tremens, delirium ebri- osum, cophalalgis ebriosorum, carre to show their gastric complications, and the importance of addreasing their treatment to the stomach and chylopoietic viscern, iustead of to the heart and brain by blooding and narcoticn. These diseases are three, of a class produced by the abuse of alcohol, commencing with acute dyspepsia, and culminating in phrenitis or in mania : and the main object in their treatment should be to restore a healthy state of the blood and circulation; as, for example, in the brief summary of the following cases of delirium tremens, which is one of the most usual of these diseases that comes under medical care.

CASE I. A married man, aged 35, warehouseman, with a family, having had previous attacks, shortly after one of his immoderate potations of brandy was seized, about 10 P.X. in summer. Lying opposite to a window, he complained of frightful objects coming through it to torment him. Pulse 130 ; great restlessness and pervigilium.

B Pulv. rhei Эss; pulv. pot. sulph. Эj. Fint pulvis 8 ris hor. sumendus.

B Liq. ammon. acet. $\zeta i j$; mist. camphorat. ziij ; syr. juj; sp. æth. nitr. 3 ij; aquæ 3 jj. M. Cap. cochl. larg. 4 tis horis.

To relieve the phrenitic symptoms, ordered-

Applicentur sinapismi carpis singulis et stupa terebinthina nuchæ.

To abstain from all alcoholic drinks, and to have toast water or milk and water. Next day he was able to take broth, which appeared to be of saving efficacy; the debility, owing to the long continued dyspepsia, being removed, and a cure effected in two days.

CASE Ir. A publican, aged 42, married, without family, attacked in the same summer as was Case $I$. Great prostration; bowels torpid.

B Magnes. sulph. $\mathbf{3}^{\mathrm{x}}$; quin. sulph. gr. iij; coccinell. gr. ij. M. et div. in chart. viij, sumatur $j 4$ tis horis.

In addition, ordered the same remedies as above. This man recovered after a week's illness.

CAsE III. A man, aged 70, in whom every muscle appeared to be tremulous. Pulse rapid; excessive pain at the occiput; maniacal.

Subjiciatur caput largo canali. Applicentur sinapismi sing. carp. Habeat infus. anthem. pro potu.

Bo Pulv. jalapæ co. ziss stat. sumendus.

These were ordered in the morning. In the afternoon, he came down stairs, but no effect from the powder. Pulse below 90 . Ordered the pediluvium cal.

B Ext. col. co., pil. hyd., àā gr. v. Fiat pil. ij. horis somnis sumendus.

Bo Pulv. rhei $\mathfrak{j}^{\text {ss }}$; pulv. potass. sulph. jj. Fiat. pulv. p. m. sum.

Applicetur emp. lytt. nuchæ.

After the operation of the cathartic, the following was ordered; and he recovered after a few days' illness.

Bo Magnes. sulph. そj; mist. camp. $\zeta$ viij; sp. æth. nitr. $\jmath^{i j}$. M. Fiat. mist.

Rexarks. The carbonic acid, given in the usual way, is an efficient contrastimulant in this disease; and I should place confidence in tartar emetic, especially in a case like Case III, as recommended by some authors. The following may be the principles of treatment deducible from the recults of the above mode of treatment.

1. To calm and give tone to the stomach and chylqpoietic viscera.

2. To restore the blood to a healthy state by nutrient diet and external counterirritation.

3. To avoid the use of narcotics, which embarrass the respiration still further.

Barnaley, Octobor 1855. 